\title{
PENINGKATAN KOMPETENSI GURU DAN SISWA SMK PGRI SINGOSARI KABUPATEN MALANG MELALUI PELATIHAN SOFTWARE ETAP
}

\author{
Lauhil Mahfudz Hayusman ${ }^{1)}$, Taufik Hidayat ${ }^{2)}$, I Made Wartana ${ }^{3)}$, Teguh Herbasuki ${ }^{4)}$ \\ ${ }^{1), 2)}$ Program Studi Teknologi Listrik DIII, Fakultas Teknologi Industri, Institut Teknologi Nasional Malang \\ ${ }^{3), 4)}$ Program Studi Teknik Elektro S-1, Fakultas Teknologi Industri, Institut Teknologi Nasional Malang
}

\begin{abstract}
Abstrak Sekolah menengah kejuruan (SMK) adalah sekolah yang berbasis praktek, yang mempersiapkan peserta didiknya dengan latihan-latihan keterampilan, pengembangan bakat dan pendidikan karakter untuk siap bekerja, bekerja mandiri, dan mengikuti pendidikan lebih lanjut sesuai dengan kejuruannya. Agar bisa bekerja secara efektif dan dapat bersaing di dunia kerja, lulusan SMK juga harus memiliki kompetensi / "nilai tambah". Hal tersebut bisa tercapai dengan peran aktif guru dalam mengembangkan keahlian dan keterampilannya dalam menunjang proses belajar mengajar di kelas, salah satu nilai tambah yang harus dimiliki oleh siswa adalah kamampuan dalam penggunaan software aplikatif. Salah satu software yang banyak dipakai di kalangan industri, praktisi dan akdemisi yaitu software ETAP. ETAP adalah software yang digunakan untuk melakukan pemodelan, perencanaan dan evaluasi sistem kelistrikan yang ada di suatu industri, jaringan tenaga listrik dan pembangkit yang dapat bekerja secara offline dengan data-data real (data lapangan) sebagai input sehingga ketika merancang menggunakan ETAP, seorang engineer dapat mengambil keputusan sesuai dengan data atau hasil analisis yang didapat. Jumlah peserta yang mengikuti pelatihan ini sebanyak 21 Siswa dari Program Keahlian Teknik Ketenagalistrikan, Paket Keahlian Teknik Otomasi Industri dan dilaksanakan selama 3 hari
\end{abstract}

Kata Kunci: Sekolah Menengah Kejuruan, software aplikatif, software ETAP.

Perkembangan ilmu pengetahuan dan teknologi saat ini sangat membutuhkan sumber daya manusia yang siap kerja dan berkompeten dibidangnya. Untuk menghasilkan sumber daya manusia yang berkualitas maka tidak terlepas dari peran serta suatu lembaga pendidikan. Satu diantara lembaga pendidikan yang mengacu pada pengembangan kualitas sumber daya manusia adalah Sekolah Menengah Kejuruan (hayusman dkk, 2017).

SMK merupakan sekolah kejuruan yang tugasnya mendidik dan mencetak sumber daya manusia yang siap bersaing di dunia pekerjaan. Permasalahan SMK saat ini umumnya terkait dengan keterbatasan peralatan, masih rendahnya biaya praktek, dan lingkungan belajar yang tidak serupa dengan dunia kerja (Mulyana, 2014). Disamping itu, kondisi SMK saat ini hanya menyelenggarakan fungsi tunggal yaitu menyiapkan siswanya untuk bekerja pada bidang tertentu sebagai karyawan, lemah dalam menyiapkan siswanya untuk menjadi wirausaha, lambat daya tanggapnya terhadap dinamika tuntutan pembangunan ekonomi, dan belum ada kepastian jaminan terhadap siswanya untuk memperoleh pekerjaan yang layak (Slamet, 2013). SMK sangat dekat hubungannya dengan teknologi (baik teknologi hardwere maupun teknologi software) karena teknologi merupakan alat utama dan teknologi merupakan bagian dari kehidupan SMK. Teknologi saat ini sarat perubahan menuntut SMK memliki daya adaptasi dan adopsi yang cepat agar mampu menyiapkan siswanya untuk melek teknolgi, luwes menghadapi perubahan teknologi dan trampil dalam mengoperasikan teknologi. Salah satu teknologi software aplikatif yang banyak digunakan di dunia industri adalah ETAP (Electrical Transient Analysis Program)

ETAP merupakan suatu perangkat lunak (software) yang mendukung sistem tenaga listrik. Perangkat ini mampu bekerja dalam keadaan offline untuk simulasi tenaga listrik, online untuk pengelolaan data real-time. Fitur yang terdapat di dalamnya-pun bermacammacam antara lain fitur yang digunakan untuk 
menganalisa pembangkitan tenaga listrik, sistem transmisi maupun sistem distribusi tenaga listrik. ETAP ini awalnya dibuat dan dikembangkan untuk meningkatkan kualitas keamanan fasilitas nuklir di Amerika Serikat yang selanjutnya dikembangkan menjadi sistem monitor manajemen energi secara real time, simulasi, kontrol, dan optimasi sistem tenaga listrik, (Awaluddin, 2007). ETAP dapat digunakan untuk membuat proyek sistem tenaga listrik dalam bentuk diagram satu garis (one line diagram) dan jalur sistem pentanahan untuk berbagai bentuk analisis, antara lain: aliran daya, hubung singkat, starting motor, transient stability, koordinasi relay proteksi, sistem harmonisa dan lain sebagainya.

Tujuan kegiatan ini adalah memberikan pelatihan dasar tentang penggunaan software ETAP untuk mendesain, memodelkan dan menganalisis sistem kelistrikan.

Manfaat yang diharapkan dari kegiatan pengabdian masyarakat ini adalah (1) Menambah wawasan dan kemampuan siswa dan Guru SMK Nasional dalam penggunaan software aplikatif, khususnya dalam melakukan perancangan dan analisis sistem tenaga listrik. (2) Menjadi nilai tambah bagi lulusan SMK Nasional dalam mencari pekerjaan (3) Bagi pelaksana, merupakan bentuk realisasi salah satu unsur tridharma perguruan tinggi yaitu pengabdian kepada masyarakat berupa pemberian pelatihan software ETAP (4) Menjadi sarana untuk turut serta meningkatkan kualitas lulusan siswa SMK Nasional Malang.

\section{METODE PELAKSANAAN}

\section{Kerangka Pemecahan Masalah}

Penerapan teknologi dalam Pelatihan software ETAP bagi Siswa dan Guru SMK PGRI Singosari Kabupaten Malang yaitu dengan cara pembuatan modul. Modul yang dibuat tersebut digunakan siswa dan guru sebagai panduan dalam mempelajari software ETAP secara bertahap, mulai dari:

a. Penggunaan software ETAP untuk memodelkan sistem real: Jaringan distribusi, penghantar, beban resistif dan induktif, transformator, relay, current transformer (CT), Pemutus Tenaga (PMT)

b. Mengidentifkasi letak permasalahan yang terjadi pada sistem yang sudah dimodelkan dengan bantuan analisis aliran daya (load flow).

c. Memberikan solusi yang terbaik (merubah jenis dan luas penampang penghantar, mengubah sadapan trafo, pemasangan kapasitor bank dll) dari permasalahan yang ditemukan berdasarkan teori-toeri, pengalaman yang sudah didapatkan di bangku pelajaran, pengalaman guru dan para instruktur

d. Pengenalan software ETAP,

\section{Realisasi Pemecahan Masalah}

Adanya transfer pengetahuan dan teknologi dari perguruan tinggi dan masyarakat pengguna teknologi khususnya Siswa dan Guru SMK PGRI Singosari. Melakukan pendampingan dalam transfer pengetahuan dan teknologi, mulai pemberian materi, pemberian pelatihan dan evaluasi sampai dengan keberhasilan program sesuai tujuan dari kegiatan pengabdian kepada masyarakat oleh Perguruan Tinggi.

Sedangkan kriteria keberhasilan program penerapan IPTEKS bagi masyarakat ini dapat diuraikan sebagai berikut:

a. Pemahaman dan kemampuan siswa dan Guru SMK PGRI Singosari bertambah sehingga Guru bisa memberikan ilmu penggunaan software ETAP kepada siswa - siswa lainya setelah kegiatan ini berakhir.

b. Lulusan SMK bisa bekerja mandiri dengan membuka jasa konsultan di bidang sistem tenaga listrik.

c. Siswa SMK mempunyai motivasi untuk melanjutkan studi di ITN Malang khususnya di program studi Teknik Elektro.

\section{Waktu Pelaksanaan Kegiatan}

Pelaksanaan kegiatan pelatihan ini dilaksanakan selama 3 hari, setiap harinya kegiatan pelatihan ini berlangsung selama kurun waktu 2 jam. Mengingat keterbatasan dan kesesuaian jadwal antara jam sekolah siswa dan kegiatan lainnya. Pemilihan hari pelaksanaan pelatihan hanya dimungkinkan di hari senin, selasa dan rabu. Untuk sarana dan prasarana pelaksanaan pelatihan ini, digunakan di ruang kelas Program Keahlian Teknik Ketenagalistrikan SMK PGRI Singosari Kabupaten Malang.

\section{Khalayak Sasaran}

Khalayak sasaran dalam kegiatan pengabdian kepada masyarakat, sebagai berikut: 
a. Guru yang berada di Program Keahlian Teknik Ketenagalistrikan, Paket Keahlian Teknik Otomasi Industri berjumlah 1 orang.

b. Siswa Program Keahlian Teknik Ketenagalistrikan, Paket Keahlian Teknik Otomasi Industri berjumlah 21 orang.

\section{Metode Yang Digunakan}

Metode kegiatan PHPM pelatihan software ETAP bagi siswa dan guru SMK Nasional Malang sebagai berikut:

a. Pemberian materi, meliputi:

- Pengenalan Program ETAP.

- Load flow analysis.

- Jaringan Distribusi.

- Load Tap Changer dan Kapasitor Bank.

- Sistem Proteksi Tenaga Listrik

b. Tanya jawab / Diskusi

Setelah diberikan materi, peserta diberikan kesempatan untuk mengajukan pertanyaanpertanyaan mengenai materi yang masih kurang jelas atau kurang dimengerti.

c. Pelatihan Software ETAP

Secara bersama-sama melakukan pemodelan sistem ke dalam software ETAP sesuai dengan materi yang telah disampaikan. Dibantu oleh instruktur dan didukung dengan modul yang telah disiapkan oleh tim pelaksana, agar peserta bisa lebih memahami cara memodelkan setiap komponenkomponen kelistrikan menjadi satu kesatauan sistem menggunakan software ETAP.

d. Evaluasi

Proses pelatihan dilakukan dengan panduan modul. Untuk mengetahui tingkat ketercapaian tujuan pelatihan dilakukan dengan evaluasi. Evaluasi dilakukan bersamaan dengan proses pelatihan, artinya setiap peserta yang mengikuti pelatihan dipantau oleh 2 instruktur, yang langsung dibimbing apabila mengalami kesulitan. Pada proses pelatihan peserta diberi penjelasan awal, kemudian dibimbing dalam melaksanakan setiap perintah dan tugas latihan yang ada di modul. Setiap langkah tersebut dinilai dengan lembar evaluasi.

e. Pemberian Sertifikat

Peserta pelatihan software ETAP setelah selesai mengikuti kegaiatan tersebut, akan diberikan sertifikat pelatihan yang di tandatangani oleh Ketua Progran Studi Teknologi Listrik DIII dan Ketua Pelaksana Kegiatan.

\section{HASIL DAN PEMBAHASAN \\ Hasil Kegiatan}

Adapun hasil kegiatan pengabdian kepada masyarakat ini adalah kemudahan dalam pemahaman dan keterampilan penggunaan software ETAP untuk memodelkan, menguji dan menganalisis sistem tenaga listrik serta memberikan solusi dan kajian awal dalam mengatasi permasalahan yang timbul pada sistem tenaga listrik. Kegiatan ini tentunya diharapkan sebagai tambahan keterampilan bagi siswa lulusan SMK PGRI Singosari dalam mencari / membuka lapangan pekerjaan atau dalam melanjutkan pendidikan ke jenjang yang lebih tinggi. Sebagai tambahan wawasan bagi guru dalam memahami software aplikatif ketenagalistrikan yang dapat mendukung dalam proses belajar mengajar.

\section{Evaluasi Keberhasilan}

Keberhasilan pelaksanaan program pengabdian kepada masyarakat ini berdasarkan beberapa hal sebagai berikut:

a. Respon positif dari siswa dan guru.

Respon peserta pelatihan dan guru dilihat dan diukur melalaui pengamatan secara lisan dan tertulis selama pelatihan berlangsung. Dengan memberikan kuesioner yang menyangkut kesan, saran dan kritik peserta pelatihan terhadap kegiatan pengabdian kepada masyarakat.

b. Bertambahnya wawasan dan keterampilan peserta pelatihan

Keterampilan peserta pelatihan selalu diamati saat pelatihan berlangsung, melalui pemberian latihan / contoh kasus di setiap materi yang diberikan.

\section{Alasan Keberlanjutan Kegiatan}

Selama pelaksanaan kegiatan pelatihan ini, mulai dari tahap persiapan sampai pelaksanaannya, dapat disampaikan beberapa hal sebagai berikut:

a. Pimpinan SMK PGRI Singosari maupun Guru Program Keahlian Teknik Ketenagalistrikan, Paket Keahlian Teknik Otomasi Industri sangat antusias menyambut dengan baik tawaran kerjasama sebagai mitra dalam program pengabdian kepada masyarakat berupa pelatihan software ETAP. Pihak SMK PGRI Singosari berharap program ini dapat dilaksanakan secara berkelanjutan di tahun-tahun berikutnya 
dengan materi-materi lainya, seperti pelatihan software AUTOCAD, SCADA.

b. Materi pelatihan yang diberikan disusun sedemikian rupa dengan tingkatan / level yang mudah dipahami oleh siswa-siswa Program Keahlian Teknik Ketenagalistrikan yang disertai dengan contoh-contoh permasalahan dan cara mengatasinya berdasarkan teori-teori yang telah siswa dapatkan di bangku sekolah.

c. Situasi dan kondisi pelatihan sangatlah kondusif sehingga peserta pelatihan dapat menyerap materi-materi yang disampaikan.

d. Rasa ingin tahu peserta pelatihan yang sangat tinggi, terlihat dari hasil evaluasi yang dilakukan selama pelatihan berlangsung. Peserta pelatihan dapat mengikuti dan mengerjakan setiap latihan serta contoh kasus yang diberikan dengan baik.

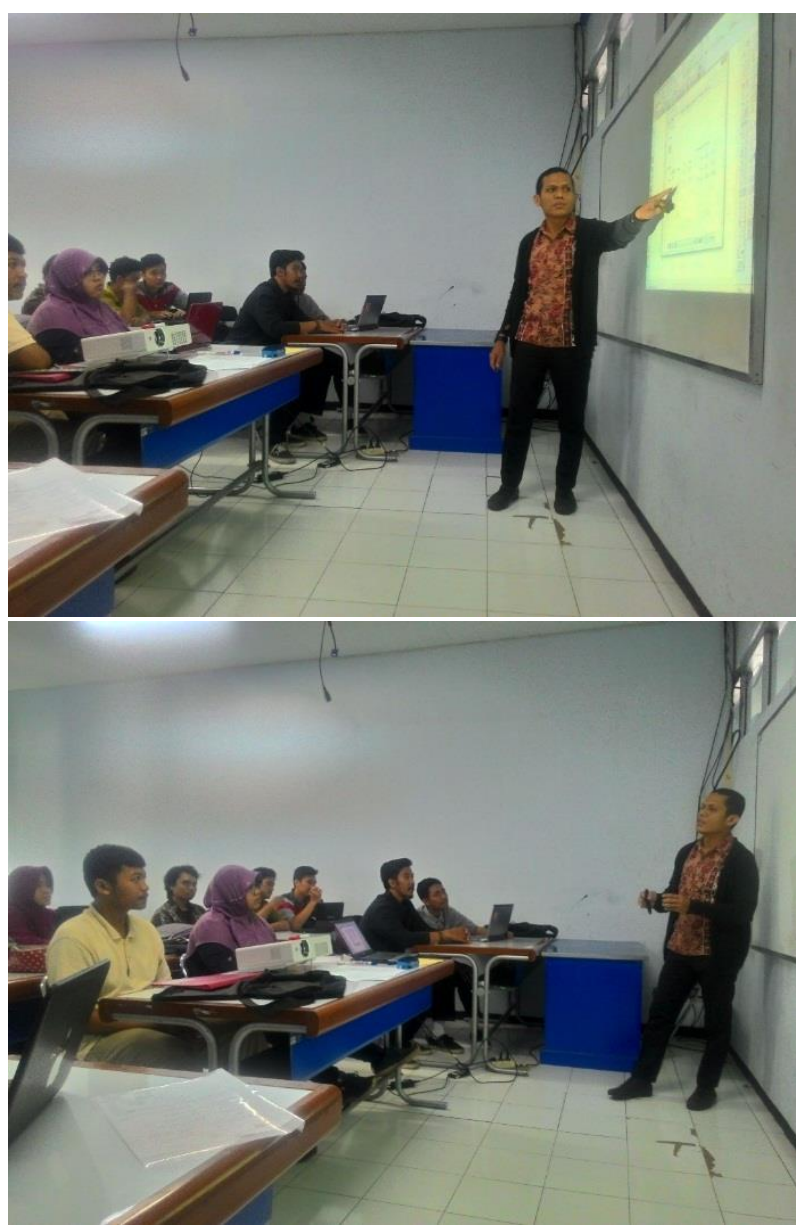

Gambar 1. Penyampaian materi pelatihan oleh Dosen T. Listrik DIII ITN Malang
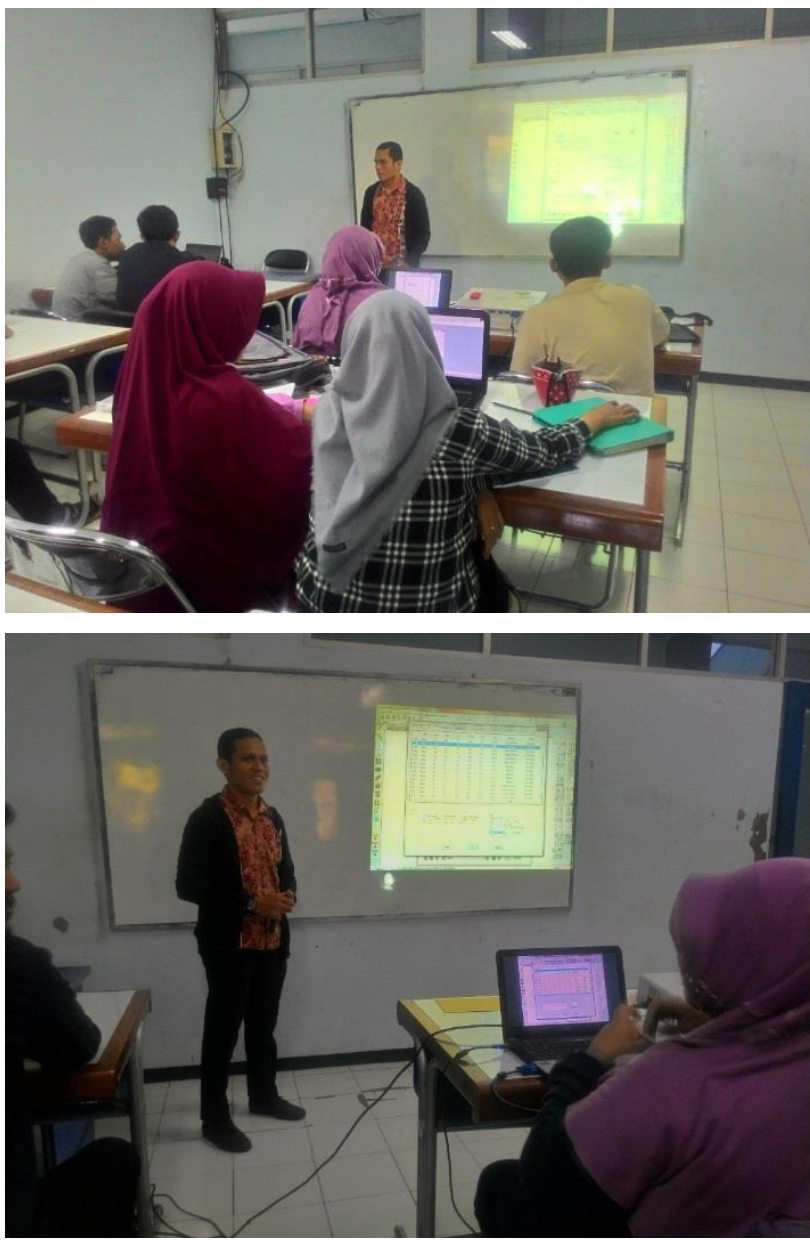

Gambar 2. Proses tanya jawab pada saat pelatihan

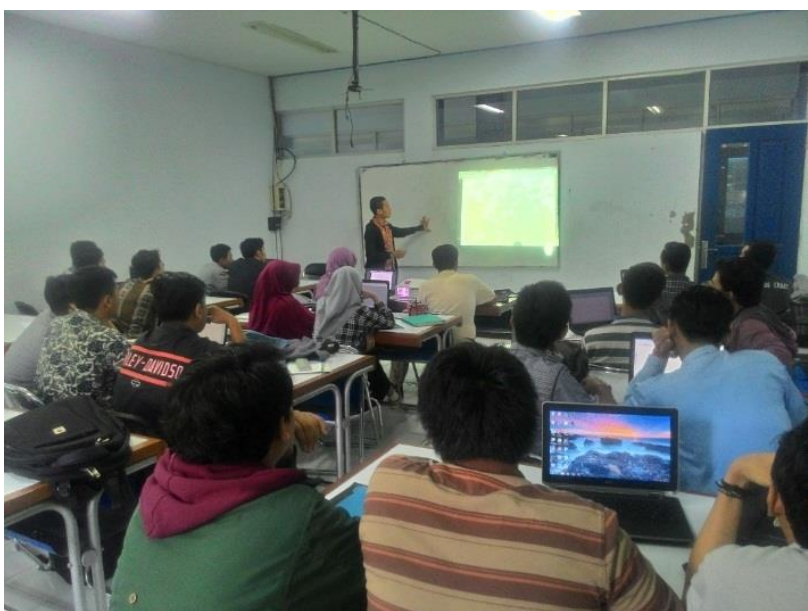




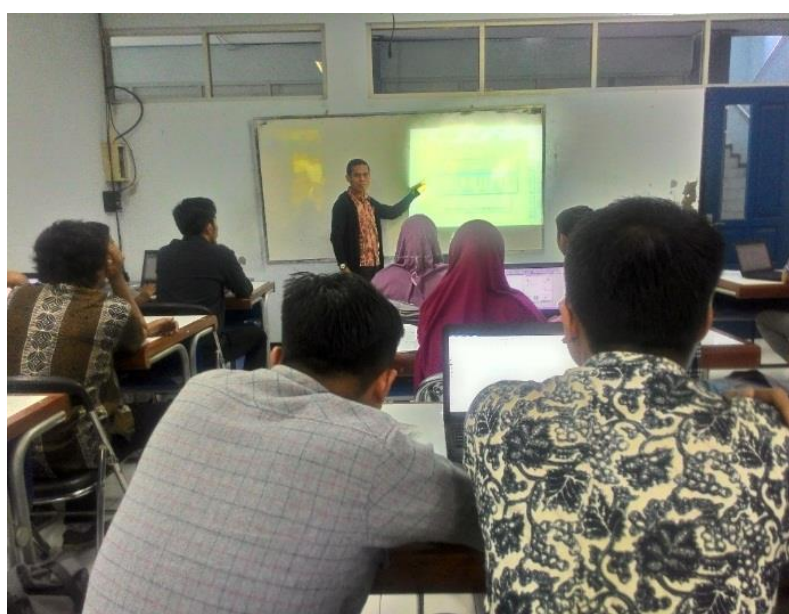

Gambar 3. Peserta pelatihan menyimak materi yang disampaikan instruktur

\section{KESIMPULAN \& SARAN}

\section{Kesimpulan}

1. Kegiatan pelatihan ini sangat bermanfaat bagi siswa dan guru Program Keahlian Teknik Ketenagalistrikan, Paket Keahlian

5. sistemmatis dan mudah dipahami oleh para siswa.

\section{Saran}

Berikut ini adalah beberapa hal yang perlu disarankan untuk keperluan pengembangan pelatihan selanjutnya, yaitu:

1. Kegiatan seperti ini sebaiknya dilaksanakan secara berkesinambungan, mengingat minat siswa dan guru sangat tinggi akan pengetahuan keterampilan software aplikatif tenaga listrik.

2. Alokasi waktu yang relatif pendek yaitu hanya 3 hari dengan durasi waktu 2 jam dirasakan masih kurang efektif, sehingga diharapkan kegiatan pelatihan selanjutnya dapat mengalokasikan waktunya lebih banyak lagi.

\section{DAFTAR PUSTAKA}

Ardiani, Prima.R dan Multa, Lesnanto. 2013. Modul Pelatihan Etap. Jurusan Teknik
Teknik Otomasi Industri, karena dapat memberikan wawasan dan menambah keterampilan dalam penggunaan software ETAP.

2. Kemampuan penggunaan software aplikatif (Software ETAP) dapat dijadikan sebagai tambahan keterampilan dalam mencari pekerjaan dan mengajar bagi para guru.

3. Minimnya pengetahuan para guru tentang software-software aplikatif khususnya software ETAP sehingga belum pernah diajarkan ke siswa.

4. Tidak semua siswa memiliki pola pemikiran yang cepat dalam belajar, terutama pemahaman tentang penggunaan/pengoperasian software aplikatif (Software ETAP) sehingga menuntut kami selaku instrukutur untuk menyajikan materi pelatihan yang lebih sederhana,

Elektro dan Teknologi Informasi Universitas Gadjah Mada. Yogyakarta.

Bakhtiar, Reza dan Wahyu, Lukita. 2010. Modul Pelatihan ETAP 6.0. Jurusan Teknik Elektro. Universitas Muhamadiah Yogyakarta.

Hayusman, M. L dkk. 2017. Pelatihan Software ETAP (Electrical Transient Analyzer Program ) bagi Siswa dan Guru SMK Nasional Malang. Jurnal Industri Inovatif. Vol.7, No.1, Hal. 7-11.

Mulyana, Elih. 2014. Kesesuaian Kamampuan Lulusan SMK di Dunia Kerja (Studi Kasus pada Kontraktor Listrik di Jawa Barat). Prosiding Konversi Nasional Asosiasi Pendidikan Teknolosi dan Kejuruan (APTEKINDO) ke 7 FPTK Universitas Pendidikan Indonesia. Bandung.

PH, Slamet. 2013. Pengembangan SMK Model untuk Masa Depan. Cakrawala Pendidikan, Th XXXII, No. 1. Fakultas Teknik Universitas Negeri Yogyakarta. 